\title{
Uso de contracepção por mulheres de diferentes grupos religiosos: diferenças ou semelhanças?
}

\author{
Use of contraception by women of different religious groups: differences or \\ similarities?
}

\author{
Ingrid Gomes Dias da Costa* \\ Angelita Alves Carvalho **
}

\begin{abstract}
Resumo
As religiões são consideradas um fator cultural importante para a determinação das atitudes e comportamentos dos indivíduos, o que por sua vez pode ter influência em muitas variáveis sociodemográficas como: sexualidade, casamento, contracepção, aborto, dentre outras. Uma variável importante que pode ser influenciada pela religião é o uso de contracepção, gerando padrões contraceptivos diferenciados por segmento religioso. A religião possui diversos mecanismos de influência na vida dos fiéis, entre eles, as normas e diretrizes, bem como sansões e coação. Este estudo tem o objetivo de identificar e analisar os possíveis diferenciais no uso de contracepção segundo religiões entre mulheres sexualmente ativas no país. Para isso foram utilizados dados da Pesquisa Nacional de Demografia e Saúde da Criança e da Mulher de 2006 e modelo de regressão logística binomial. Os resultados sugerem que as mulheres católicas usavam mais contracepção moderna, principalmente hormonal. Já as evangélicas usavam mais contracepção tradicional, esterilização e camisinha. Dessa forma, apesar da igreja católica ser contra o uso de contracepção moderna, suas normas parecem não influenciar tanto o comportamento contraceptivo das fiéis. Outra inferência é que a baixa frequência aos cultos pode gerar pouco comprometimento e levar a uma relativização doutrinária.
\end{abstract}

Palavras-chave: religião; contracepção.

\begin{abstract}
The religions are considered an important cultural factor to determination of the individuals' attitudes and behaviors, which in its turn can influence in many social and demographic variables such as sexuality, marriage, contraception, abortion, among others. An important variable that could be influenced by religion is the use of contraception, generating patterns differentiated by religious segment. Religion has several mechanisms of influence in the lives of practitioners of a faith, among them the rules, guidelines, sanctions and coercion. This study aims to identify and analyze possible differences in contraceptive use by religions between sexually active women in the Brazil. We used data from the National Survey of Demography and Health of Children and Women 2006 and binomial logistic regression model. The results suggest that Catholic women used more modern contraception especially hormonal options. Already evangelical women used more traditional contraception and sterilization. Thus, although the Catholic Church is against the use of modern contraception, its rules do not seem to influence the contraceptive behavior of faithful. Another inference relates to the fact that low frequency on cults may generate little commitment and lead to doctrinal relativism.
\end{abstract}

Keywords: religion; contraception.

Artigo recebido em 23 de agosto de 2014 e aprovado em 21 de outubro de 2014.

* Doutoranda em Demografia, com mestrado e graduação pela UFV. País de origem: Brasil. E-mail: ingridgdias@yahoo.com.br.

** Doutora em Demografia. Pesquisadora em Informações Geográficas e Estatísticas na Escola Naiconal de Ciências Estatísticas (ENCE/IBGE). País de origem: Brasil. E-mail: litaacarvalho@yahoo.com.br.

Horizonte, Belo Horizonte, v. 12, n. 36, p. 1114-1139, out./dez. 2014 - ISSN 2175-5841 


\section{Introdução}

A análise das preferências reprodutivas tem sido objeto de estudo em diversas pesquisas, pois é um tema ligado diretamente à fecundidade e consequentemente ao entendimento da dinâmica demográfica. A implementação das preferências reprodutivas requer o conhecimento sobre o uso e a necessidade de métodos contraceptivos, que são instrumentos de regulação da fecundidade. Segundo Bankole e Westoff (1998), somente há aproximadamente três décadas a questão dos métodos de regulação da fecundidade e a das preferências reprodutivas têm sido incluídas em pesquisas sobre fecundidade nos países em desenvolvimento. A consequência da inserção tardia desse tema na esfera científica é o limitado número de pesquisas, principalmente envolvendo análises e comparações por diferentes categorias, como por exemplo, a associação de fenômenos demográficos e religião.

A maioria dos estudos existentes envolvendo essas duas temáticas foi realizada nos Estados Unidos e na Europa. Essas pesquisas concluíram que a religião pode influenciar positivamente no comportamento dos fiéis por meio da adoção de estilos de vida saudáveis (ELLISON; LEVIN, 1998, REGNERUS, 2003) ou de forma negativa, gerando sentimento de culpa ou constrangimento das pessoas devido a coerção e cobrança dos membros que apresentarem comportamento desviante (KRAUSE; ELLISON; WULFF, 1998, KRAUSE; ELLISON, 2009). Estudos mostram que a influência da religião na vida dos fiéis se daria por meio de princípios de moral, ensinamentos, normas, modelos de comportamento e mecanismos de coação adotados (VERONA, 2010; McQUILLAN, 2004).

No Brasil, pesquisas sobre comportamento demográfico e religião ainda são poucas (WOOD; WILLIAMS; CHIJIWA, 2007, VERONA, 2010, ZANATA 2011), principalmente envolvendo a influência da religião no uso de contracepção pelos fiéis. Os estudos existentes sobre essa temática, em sua maioria, se concentram no 
comportamento sexual e fecundidade entre adolescentes (MIRANDA-RIBEIRO et al, 2009; McKINNON; POTTER; GARRARD-BURNETT, 2008).

Fatores religiosos e culturais têm o potencial de influência muito grande quanto à aceitação e o uso de contraceptivos por casais de diferentes origens religiosas de maneiras muito distintas. Dentro das religiões, as diferentes seitas podem interpretar os ensinamentos religiosos sobre o assunto de maneiras variadas, e as mulheres e os seus parceiros podem optar por ignorar os ensinamentos religiosos (SRIKANTHAN; REID, 2008).

No que se refere aos métodos contraceptivos, a Igreja Católica condena abertamente os métodos anticoncepcionais "artificiais", sob a argumentação de que qualquer ato matrimonial deveria permanecer aberto à transmissão da vida. Dessa forma, a contracepção, até mesmo para pessoas casadas, não deve ser utilizada; e o aborto provocado, ainda que para salvar a vida da mulher, nunca é justificado moralmente e nunca deveria ser considerado legal. No contexto das Igrejas Evangélicas, após a Segunda Guerra, estas passam a reconhecer o uso de métodos contraceptivos modernos desvinculados do sexo ilícito, do adultério e da prostituição. Já as Igrejas Evangélicas Pentecostais se caracterizam pela recusa às idéias mais "liberais". Assim como a Igreja Católica, as Igrejas Evangélicas Pentecostais, de forma geral, condenam a possibilidade de adoção do aborto como prática que se insere dentro da ordem do pecado e do delito/crime (JARDIM, 2011).

Sabendo dessa influência da religião, acredita-se que no Brasil as mulheres sejam influenciadas pela religião em suas decisões quanto ao uso e tipo de método contraceptivo e que essa influência não se daria da mesma forma para todas as religiões.

Diante disso, problematiza-se se o comportamento reprodutivo das mulheres pode ser afetado de maneiras diferentes de acordo com seu segmento religioso e questiona-se: a prática contraceptiva é diferenciada de acordo com a religião das mulheres? Quais religiões fazem mais uso de contracepção? Qual o 
método mais utilizado pelas mulheres em cada grupo religioso? A frequência a cultos e cerimônias religiosas e o fato da mulher ser ou não convertida afetam o uso de contraceptivos?

Acredita-se que as respostas a essas perguntas, buscadas por nossa pesquisa, possibilitam vislumbrar a importância da religião perante as decisões contraceptivas e entender se realmente as normas e valores transmitidos aos seguidores atuam como mediadores do comportamento reprodutivo. Além disso, poucos estudos exploram as diferenças quanto ao uso de contracepção por religião no Brasil.

O objetivo principal deste estudo foi identificar e analisar os possíveis diferenciais no uso de contracepção segundo religiões entre mulheres sexualmente ativas no Brasil.

\section{Referencial teórico}

\subsection{Contracepção no Brasil}

A contracepção pode ser analisada sob dois aspectos: um deles seria a limitação da fecundidade e outro como importante componente da saúde da mulher. De acordo com Aguirre (2003), o planejamento da fecundidade pode contribuir para a melhoria da saúde da mulher, proporcionando orientação e informação não somente sobre os métodos contraceptivos, mas também sobre o comportamento sexual e reprodutivo como um todo. Para o autor, é nessa visão que surge um novo conceito para a reprodução cujo eixo é sustentado em duas categorias: saúde reprodutiva e direitos reprodutivos.

No intuito de assegurar a implementação das preferências reprodutivas, sexuais e de saúde dos casais foi que surgiram as conferências mundiais de população, em especial a Conferência do Cairo em 1994, que ajudaram a construir um dos princípios fundamentais da reprodução humana, o direito sexual e 
reprodutivo. Conforme a Conferência do Cairo, o casal tem o direito a ter o número de filhos que deseja, no momento que considere conveniente. Assim os direitos reprodutivos e sexuais se baseiam no reconhecimento do direito básico de todos os casais e indivíduos, o de decidirem livre e responsavelmente sobre o número, espaçamento e quando devem ter seus filhos por meio do acesso à informação de como fazê-lo, bem como o direito de se beneficiarem da saúde sexual e reprodutiva do mais alto nível. Além de resguardar a igualdade entre mulheres e homens no que diz respeito à relação sexual e reprodução, incluindo-se o respeito à integridade, respeito mútuo, consentimento e divisão de responsabilidades pelos comportamentos sexuais e suas conseqüências (UNITED NATIONS, 1994).

De acordo com Pedro (2003), no Brasil, diferentemente do que ocorreu nos países europeus, o movimento feminista não se articulou para que os métodos contraceptivos fossem liberados para o uso, mas sim para exigir do governo a garantia do acesso, não só aos métodos, mas também a uma série de serviços que contemplassem a saúde sexual e reprodutiva. Assim, para a maioria da população o acesso às informações e aos métodos contraceptivos ficou muito restrita ao mercado privado, o que indicou grandes desigualdades socioeconômicas em relação ao uso de contraceptvos. Apesar disso, o Brasil é um dos países latinoamericanos de maior prevalência contraceptiva (BARROS; WONG, 2012)

Segundo Perpétuo e Aguirre (1998), o percentual de mulheres usuárias de algum método cresce de acordo com o nível socioeconômico das mesmas, sendo a esterilização o método mais utilizado em todos os níveis socioeconômicos tanto em 1986 quanto em 1996. Entretanto, percebe-se que o uso da esterilização cresceu principalmente entre os grupos menos privilegiados e nos grupos socialmente mais favorecidos houve uma tendência de diminuição da esterilização e de aumento do uso de outros métodos modernos, especialmente os hormonais.

Amorim (2009) mostrou que os métodos mais utilizados em 2006 eram os mesmos de 20 anos atrás (laqueadura e hormonais). Apesar da laqueadura ainda ser o método de maior prevalência, perdeu espaço para outros métodos. A autora sugere ainda uma inversão da trajetória ascendente da esterilização feminina, com 
os métodos masculinos ganhando cada vez mais espaço no mix contraceptivo. Entre as coortes mais jovens, assim como entre as mulheres com menor número de filhos, observa-se maior prevalência de métodos hormonais e preservativos. Já a laqueadura e também a vasectomia apresentam prevalência significativa nas coortes mais velhas, bem como entre as mulheres com maior número de filhos.

Segundo Perpétuo e Wong (2009) houve um aumento da assistência contraceptiva por parte dos serviços de saúde, mas ainda é deficitária e desigual. Houve uma expansão do uso de métodos temporários antes da esterilização, entretanto, cresceu também o percentual de mulheres que se esteriliza sem ter usado nenhum método. Com os dados de 2006 da PNDS para o Brasil, as autoras mostram que os diferenciais socioeconômicos persistiram na prática de contraceptiva, o qual foi em favor das mulheres de melhor nível de escolaridade e renda, em que havia uma prevalência de uso da esterilização masculina e da camisinha masculina. No grupo de piores condições socioeconômicas houve uma excessiva presença da laqueadura tubária entre as mulheres sem instrução; pequena participação masculina, e relativamente menor melhoria na "qualidade" da contracepção.

\subsection{Mudanças religiosas no Brasil e Influência da religião nas escolhas contraceptivas dos indivíduos.}

O Brasil tem vivido uma mudança religiosa bastante intensa nas últimas décadas, alterando o panorama das religiões. A religião católica que sempre foi maioria no Brasil vem passando por reduções no número de fiéis. Em 1991, havia 83,3\% de católicos no país. Já em 2000 havia 73,6\%, passando para 64,6\% em 2010. Por sua vez, os evangélicos passam por um crescimento acentuado, aumentando de 9\% em 1991 para 15,4\% em 2000 e passando para 22,2\% em 2010. Dessa forma, vivencia-se o fim da hegemonia católica no Brasil, um crescimento no número de evangélicos e do número de pessoas sem religião, que agora perfaz um total de 8\% da população (IBGE, 2010). 
De acordo com o estudo de Godscheider e Mosher (1998) para os EUA, existem diferenças significativas no uso de contracepção entre católicos e evangélicos. Até meados de 1960, estas diferenças eram grandes: os evangélicos utilizavam mais contracepção que os católicos (66\% e 57\% respectivamente). Existia uma maior proporção de católicos que não usavam contracepção ou que usavam métodos tradicionais. Entretanto entre 1960 e 1980 ocorreram mudanças, houve um aumento na proporção de mulheres que utilizavam algum método moderno, principalmente entre as católicas. Em 1980, 77\% das evangélicas usavam contracepção moderna em comparação com 75\% das católicas. O estudo concluiu que os evangélicos apresentavam maior nível de esterilização do que os católicos. Segundo os autores, os católicos utilizam mais a pílula, o diafragma e a camisinha como métodos contraceptivos do que os evangélicos.

$\mathrm{Na}$ Índia, o estudo de Iyer (2002), mostrou que enquanto a religião exerce uma influência na adoção de anticoncepcionais na média, este efeito não foi confirmado entre hindus e muçulmanos depois de controlar o efeito de outros fatores socioeconômicos. Contrariamente, na zona rual de Gana, mudanças institucionais que levaram o crescimento de religioes mais tradicionais na região e a adoção destas por parte da população local parece ter contribuido para a diminuição do desejo por limitação da fecundiade e consequentemente menor uso de métodos contraceptivos. Ou seja, neste estudo houve uma forte assonciação entre mudanças na religião e mudanças no comportamento reprodutivo dos seguidores (DOCTOR et al., 2009).

De acordo com Agadjanian (2012), em Moçambique a filiação religiosa não é um fator determinante no uso de contracepção. $O$ estudo revelou que, independentemente da sua filiação religiosa, as determinantes mais importantes do uso de anticoncepcionais em Moçambique são características sociais, como a educação.

O estudo de Santos (2008), que utilizou dados transversais provenientes de questionários aplicados a 4.078 jovens entre 14 a 24 anos nas cidades de São Paulo, Porto Alegre, Campo Grande e Recife, revelou que a religião não foi 
estatísticamente significativa para o uso da camisinha tanto como contracepção quanto para prevensão de doenças sexualmente transmissíveis. A religiosidade também não foi significativa para o uso de camisinha. Entretanto, os resultados mostraram que os jovens com alto grau de religiosidade atrasam o início da vida sexual.

Esse panorama parece indicar uma relativização das doutrinas católicas pelos fiéis, que passaram a usar mais métodos modernos apesar da oposição do catolicismo. Já a religião evangélica não condena o uso de contracepção, ao contrário, os casais são orientados a realizarem o planejamento familiar no intuito de terem o número de filhos que eles tenham condição financeira e de tempo para cuidar (SOCIEDADE MISSIONÁRIA LUTERANA, 2012).

\section{Material e método}

\subsection{A base de dados}

Neste estudo, utilizaram-se os dados da Pesquisa Nacional de Demografia e Saúde (PNDS, 2006) que é uma pesquisa de amostra probabilística, selecionada aleatoriamente em dois estágios: no primeiro estágio, selecionaram-se os setores censitários, com probabilidade proporcional ao número de domicílios em cada setor e, no segundo, os domicílios, considerando a representatividade dentro de cada setor.

O universo do estudo foi formado por domićlios particulares permanentes em setores comuns (inclusive favelas), com a presença de mulheres de 15 a 49 anos de idade para todo o país. Possui informações sobre a saúde sexual e reprodutiva das mulheres, informações específicas de uso de contraceptivos, bem como 3 variáveis de religião: religião atual, frequência religiosa e religião em que foi criada. 
As variáveis selecionadas para análise neste estudo foram: religião atual, mulheres sexualmente ativas, uso de método contraceptivo atual e tipo de método contraceptivo atual; além de outras variáveis de contexto sociodemográfico e econômico das mulheres (QUADRO 1).

Com relação ao fator de expansão da amostra (peso), também de acordo com o relatório técnico da PNDS 2006, o indicado para análises que envolvam informações de mulheres é a utilização do peso para a mulher (variável XM999_Peso). Para as análises foi utilizado o fator normalizado, dividindo-se cada peso pela divisão do valor do número de casos expandidos pelo valor da amostra. Assim, as estatísticas ficaram com o mesmo número da amostra, contudo com a distribuição da população (valor expandido) (PNDS, 2006).

Ao todo, a PNDS conta com 56.365 observações, sendo que apenas 15.575 estão relacionadas às mulheres. Destas, foram utilizadas 12.118 observações referentes ao número total de mulheres sexualmente ativas. Destas, 9.461 mulheres eram casadas ou unidas e 2.657 não eram casadas ou unidas, mas eram sexualmente ativas. A partir dessas, foram feitas algumas análises de estatísticas descritivas a fim de verificar as variáveis acima listadas e suas diferenças por religião.

\subsection{Metodologia}

As análises foram feitas em relação à distribuição das mulheres por uso de métodos anticoncepcionais, religião atual, frequência a cultos e cerimônias religiosas e conversão. Para tanto, filtrou-se na base de mulheres aquelas que eram sexualmente ativas, separando-as por tipo de religião, que neste estudo foram católicas, protestantes tradicionais, evangélicas pentecostais, sem religião e outras. Em seguida foram selecionadas as que estavam usando algum método de contracepção e as que não estavam. Dentre as que usavam algum método, identificou-se o tipo de método segundo cada uma das variáveis de pertencimento religioso. 
Posteriormente foram elaborados alguns modelos de regressão logística binomial a fim de identificar a relação da afiliação religiosa atual da mulher e o uso de métodos contraceptivos, controlando-se pelas demais variáveis que também poderiam interferir nesta decisão. Segundo Gujarati (2006), as relações sociodemográficas podem ser descritas por uma única equação e um dos mais importantes modelos é o de regressão logística, baseado na transformação logit para proporção. Esse tipo de regressão é próprio para modelar variáveis que apresentam apenas duas categorias ou que foram de alguma forma dicotomizadas de tal forma que as variáveis assumem valores "o" ou "1", e são chamadas variáveis dummy. Como a variável-resposta é binária (uso ou não uso de métodos contraceptivos, uso ou não de esterilização, uso ou não de hormônios, uso ou não de camisinha e uso ou não de método tradicional), os modelos foram estimados segundo uma função logística (vide quadro 1 abaixo).

Isto é, yi é uma variável binária que assume valor 1, por exemplo no modelo geral, se a mulher utiliza contracepção, e valor zero, se a mulher não utiliza métodos, por meio da função de distribuição logística cumulativa:

$$
\left.\pi_{t}=\operatorname{Pr}\left(\mathrm{y}_{t}=1\right)=F\left(\mathrm{x}^{\prime}{ }_{t} \beta\right)=e^{x^{\prime} \beta}{ }^{\beta} / 1+e^{x^{\prime} \beta}{ }^{3}\right]
$$

Em que $\beta$ é um vetor de parâmetros a ser estimado que mensura o impacto de variações nas variáveis explicativas em xi' sobre as probabilidades de uso de método; sendo que essa função de distribuição cumulativa se restringe ao intervalo $[0,1]$. 
No modelo logístico binomial, cada coeficiente fornece o "impacto" de uma variação ocorrida nas variáveis explicativas sobre a média da variável dependente; tal efeito é conhecido como efeito marginal. Assim, com base no $\beta$ da variável indicadora religião, por exemplo, obtém-se o efeito marginal dessa variável (ser católica, por exemplo) sobre a probabilidade da mulher utilizar algum método contraceptivo (GUJARATI, 2006).

Quanto à interpretação do efeito, tem-se que um efeito marginal positivo da variável ex. 'religião' sugere que as mulheres pentecostais apresentam uma maior probabilidade de terem declarado usar métodos contraceptivos em relação às mulheres católicas. Dito de outra forma, um efeito marginal da variável indicadora da religião de $2 \%$ sobre o uso de métodos contraceptivos, por exemplo, significa que as mulheres pentecostais têm uma probabilidade $2 \%$ superior de utilizarem métodos quando comparadas às mulheres católicas. No quadro abaixo tem-se a descrição das variáveis explicativas utilizadas bem como dos modelos propostos. 
QUADRO 1 - Descrição das variáveis empregadas na análise descritiva e nos modelos de Regressão Logística

\begin{tabular}{|c|c|c|c|}
\hline \multicolumn{2}{|r|}{ Nome } & \multirow{2}{*}{$\begin{array}{l}\text { Tipo } \\
\text { Categórica }\end{array}$} & \multirow{2}{*}{$\begin{array}{l}\text { Categorias } \\
\qquad \text { o (não usa método) 1(usa método) }\end{array}$} \\
\hline $\begin{array}{l}\text { Variável resposta } \\
\text { (Modelo geral) }\end{array}$ & Uso de método contraceptivo & & \\
\hline $\begin{array}{l}\text { Variável resposta } \\
\text { (Modelo 1) }\end{array}$ & Utiliza esterilização & Categórica & o (outros) 1 (esterilização) \\
\hline $\begin{array}{l}\text { Variável resposta } \\
\text { (Modelo 2) }\end{array}$ & Utiliza hormônios & Categórica & o (outros) 1 (hormonais) \\
\hline $\begin{array}{l}\text { Variável resposta } \\
\text { (Modelo 3) }\end{array}$ & Utiliza camisinha & Categórica & o (outros) 1 (camisinha) \\
\hline $\begin{array}{l}\text { Variável resposta } \\
\text { (Modelo 4) }\end{array}$ & Utiliza métodos tradicionais & Categórica & o (outros) 1(tradicionais) \\
\hline \multirow{17}{*}{$\begin{array}{c}\text { Variáveis } \\
\text { explicativas }\end{array}$} & Região geográfica & Categórica & Norte, Nordeste, Sudeste, Sul e Centro-Oeste \\
\hline & Situação de domicílio & Categórica & Rural e Urbano \\
\hline & Estratos econômicos & Categórica & $\mathrm{AB}, \mathrm{C}$ e $\mathrm{DE}$ \\
\hline & Escolaridade da mulher & Categórica & o a 3,4 a 7,8 a 10,11 e 12 e mais \\
\hline & Religião & Categórica & $\begin{array}{c}\text { católica, protestante tradicional, pentecostal, sem } \\
\text { religião e outras }\end{array}$ \\
\hline & Frequência religiosa & Categórica & $\begin{array}{l}\text { uma ou mais vezes na semana, até três vezes ao mês } \\
\text { nunca }\end{array}$ \\
\hline & Conversão & Categórica & sim e não \\
\hline & Idade ao ser mãe & \multicolumn{2}{|r|}{ Contínua } \\
\hline & Parturição & \multicolumn{2}{|r|}{ Contínua } \\
\hline & Raça/cor & Categórica & Branca, outras \\
\hline & Trabalho remunerado & Categórica & sim e não \\
\hline & Conversa planejamento familiar & Categórica & sim e não \\
\hline & $\begin{array}{l}\text { Decisão sobre o dinheiro que a } \\
\text { mulher recebe e uso de métodos } \\
\text { contraceptivos }\end{array}$ & Categórica & ela decide, o marido decide, ambos decidem, outros \\
\hline & Palavra final & Categórica & Ela tem, o marido tem, ambos tem, ouros \\
\hline & $\begin{array}{l}\text { Diferença de idade em anos } \\
\text { entre os parceiros }\end{array}$ & \multicolumn{2}{|r|}{ Contínua } \\
\hline & Acesso à mídia & Categórica & sim e não \\
\hline & Status de fecundidade & Categórica & $\begin{array}{l}\text { Tem menos filhos do que o desejado, tem mais filhos } \\
\text { que o desejado e tem o mesmo } n^{\circ} \text { de filhos que o } \\
\text { desejado. }\end{array}$ \\
\hline
\end{tabular}

Fonte: Elaboração própria a partir dos dados da PNDS de 2006.

\section{Resultados e discussões}

A partir da TAB. 1 obteve-se o percentual de mulheres que usam e não usam métodos contraceptivos. Dentre as mulheres que usam, calculou-se o percentual 
daquelas que usam métodos modernos, tradicionais e outros tipos de métodos para cada grupo de religião. Observa-se que, de modo geral, o uso de contraceptivos é bastante elevado, independentemente da religião da mulher. Entretanto, o grupo das mulheres que mais utilizam métodos contraceptivos modernos foi o das católicas (93,26\%) seguido das mulheres sem religião com 85,36\%. As evangélicas utilizam menos contracepção moderna, sendo que as pentecostais apresentam $83,14 \%$ de utilização e as protestantes tradicionais 75,20\%.

Tabela 1 - Distribuição e uso de métodos contraceptivos para mulheres de 15 a 49 anos sexulamente ativas segundo religião atual, Brasil (2006).

\begin{tabular}{|c|c|c|c|c|c|c|c|c|c|c|c|}
\hline \multirow[b]{2}{*}{ Idade } & \multicolumn{7}{|c|}{ Métodos modernos } & \multirow[b]{2}{*}{ Outros $^{* *}$} & \multirow[b]{2}{*}{$\begin{array}{c}\text { Algum } \\
\text { método } \\
\text { tradicional }\end{array}$} & \multirow[b]{2}{*}{$\begin{array}{l}\text { Não está } \\
\text { usando } \\
\text { método }\end{array}$} & \multirow[b]{2}{*}{$\begin{array}{c}\text { Número de } \\
\text { mulheres }\end{array}$} \\
\hline & $\begin{array}{l}\text { Algum método } \\
\text { moderno }\end{array}$ & $\begin{array}{c}\text { Esterilização } \\
\text { feminina e } \\
\text { masculina }\end{array}$ & Pílula & DIU & $\begin{array}{c}\text { Injeção } \\
\text { contraceptiva }\end{array}$ & $\begin{array}{l}\text { Camisinha } \\
\text { masculina e } \\
\text { feminina }\end{array}$ & $\begin{array}{c}\text { Outros } \\
\text { modernos* }\end{array}$ & & & & \\
\hline \multicolumn{12}{|c|}{ Católicas } \\
\hline$\overline{15 \text { a } 19}$ & 81,17 & 0,00 & 35,74 & 0,14 & 4,37 & 40,65 & 0,27 & 0,40 & 0,27 & 18,15 & 769 \\
\hline 20 a 24 & 94,21 & 5,45 & 49,11 & 0,60 & 8,85 & 30,04 & 0,17 & 0,20 & 0,26 & 5,33 & 1341 \\
\hline 25 a 29 & 96,02 & 22,64 & 45,52 & 1,91 & 7,46 & 19,40 & 0,00 & 0,70 & 0,17 & 3,12 & 1429 \\
\hline 30 a 34 & 96,99 & 46,64 & 33,75 & 3,00 & 3,71 & 16,34 & 0,18 & 0,00 & 0,18 & 2,83 & 1391 \\
\hline 35 a 39 & 95,99 & 55,73 & 23,53 & 2,62 & 2,10 & 14,00 & 0,09 & 0,00 & 0,61 & 3,40 & 1299 \\
\hline 40 a 44 & 88,00 & 60,16 & 15,15 & 1,49 & 1,05 & 9,98 & 0,18 & 0,00 & 0,44 & 11,56 & 1188 \\
\hline 45 a 49 & 84,72 & 65,39 & 9,26 & 0,81 & 0,46 & 8,68 & 0,12 & 0,00 & 0,23 & 15,05 & 974 \\
\hline Total & 93,26 & 37,20 & 30,98 & 1,61 & 4,17 & 19,17 & 0,13 & 0,30 & 0,31 & 6,13 & 8399 \\
\hline \multicolumn{12}{|c|}{ Protestantes tradicionais } \\
\hline 15 a 19 & 59,72 & 0,69 & 27,78 & 1,39 & 2,08 & 27,78 & 0,00 & 0,69 & 2,08 & 37,50 & 655 \\
\hline 20 a 24 & 76,65 & 5,06 & 36,96 & 0,78 & 7,78 & 25,68 & 0,39 & 0,00 & 3,89 & 19,46 & 727 \\
\hline 25 a 29 & 81,48 & 27,16 & 29,22 & 1,23 & 6,17 & 17,70 & 0,00 & 0,41 & 3,70 & 14,40 & 472 \\
\hline 30 a 34 & 84,12 & 36,91 & 22,75 & 3,00 & 4,72 & 16,31 & 0,43 & 0,43 & 6,87 & 8,58 & 303 \\
\hline 35 a 39 & 73,86 & 43,98 & 14,94 & 0,83 & 2,90 & 11,20 & 0,00 & 0,00 & 6,22 & 19,92 & 232 \\
\hline 40 a 44 & 77,21 & 56,74 & 10,23 & 1,40 & 0,93 & 7,44 & 0,47 & 0,47 & 1,86 & 20,47 & 249 \\
\hline 45 a 49 & 65,22 & 52,80 & 6,21 & 0,00 & 0,62 & 5,59 & 0,00 & 1,24 & 2,48 & 31,06 & 200 \\
\hline Total & 75,20 & 32,07 & 21,80 & 1,27 & 3,93 & 15,93 & 0,20 & 0,40 & 4,07 & 20,33 & 2.838 \\
\hline \multicolumn{12}{|c|}{ Protestantes pentecostais } \\
\hline 15 a 19 & 86,15 & 1,54 & 27,69 & 0,00 & $4,4,62$ & 46,15 & 0,00 & 0,00 & 6,15 & 7,69 & 655 \\
\hline 20 a 24 & 69,86 & 4,78 & 35,41 & 0,48 & 6,22 & 21,05 & 0,00 & 0,00 & 1,91 & 28,23 & 727 \\
\hline 25 a 29 & 86,15 & 22,08 & 31,17 & 0,43 & 4,33 & 22,08 & 0,43 & 0,00 & 5,63 & 8,23 & 472 \\
\hline 30 a 34 & 83,79 & 42,69 & 15,02 & 1,58 & 3,56 & 16,21 & 0,00 & 0,40 & 4,35 & 11,46 & 303 \\
\hline 35 a 39 & 94,01 & 57,60 & 13,82 & 1,38 & 1,84 & 13,82 & 0,00 & 0,00 & 5,53 & 0,46 & 232 \\
\hline 40 a 44 & 89,16 & 69,46 & 7,39 & 0,49 & 0,00 & 7,88 & 0,00 & 0,00 & 3,94 & 6,90 & 249 \\
\hline 45 a 49 & 72,22 & 64,44 & 1,67 & 0,00 & 0,56 & 4,44 & 0,00 & 0,00 & 1,11 & 26,67 & 200 \\
\hline Total & 83,14 & 40,65 & 18,48 & 0,74 & 2,95 & 16,20 & 0,07 & 0,07 & 3,98 & 12,81 & 2.838 \\
\hline \multicolumn{12}{|c|}{ Sem religião } \\
\hline 15 a 19 & 89,78 & 1,46 & 37,23 & 0,73 & 12,41 & 37,96 & 0,00 & 0,00 & 0,73 & 9,49 & 92 \\
\hline 20 a 24 & 78,80 & 2,30 & 36,87 & 1,84 & 7,83 & 29,03 & 0,92 & 0,00 & 0,92 & 20,28 & 157 \\
\hline 25 a 29 & 86,73 & 19,39 & 35,71 & 2,55 & 7,65 & 20,92 & 0,51 & 0,00 & 5,10 & 8,16 & 160 \\
\hline 30 a 34 & 90,18 & 29,89 & 32,54 & 0,00 & 6,21 & 21,54 & 0,00 & 0,00 & 2,23 & 7,59 & 93 \\
\hline 35 a 39 & 84,21 & 58,95 & 11,58 & 2,11 & 3,16 & 8,42 & 0,00 & 2,11 & 3,16 & 10,53 & 80 \\
\hline 40 a 44 & 60,82 & 41,24 & 8,25 & 0,00 & 0,00 & 11,34 & 0,00 & 0,00 & 2,06 & 37,11 & 76 \\
\hline 45 a 49 & 82,98 & 59,57 & 8,51 & 2,13 & 2,13 & 10,64 & 0,00 & 0,00 & 6,38 & 10,64 & 42 \\
\hline Total & 85,36 & 23,50 & 29,40 & 1,42 & 6,99 & 23,72 & 0,33 & 0,22 & 2,73 & 11,69 & 702 \\
\hline
\end{tabular}

Fonte: Elaboração própria a partir dos dados da PNDS, 2006.

* Nota: Outros métodos incluí diafragma, pílula do dia seguinte, creme, óvulos vaginais

** Inclui outros métodos modernos e tradicionais não especificados no questionário, tais como adesivo hormonal, anel vaginal, chás, ervas, ducha vaginal, etc 
Entre os métodos modernos, de modo geral a esterilização é o método de maior utilização; contudo a pílula, a camisinha masculina e a injeção contraceptiva apresentam maior utilização pelas faixas etárias mais novas, sendo que seu uso decresce com a idade. Já as esterilizações femininas e masculinas são mais usadas por mulheres de grupos etários mais velhos, sendo que seu uso cresce com a idade. O maior uso de DIU foi observado entre mulheres de 30 a 34 e 35 a 39 anos (vide tabela 1 abaixo). A escolha do método reflete um comportamento de coorte/geração, em que as mulheres mais velhas, por já terem alcançado a sua fecundidade desejada, optam por um método contraceptivo definitivo, sendo no Brasil o mais utilizado a esterilização (Perpétuo e Wajnman, 1993).

A pílula aparece como segundo método mais usado, sendo 28,63\% para católicas, $22,51 \%$ para protestantes tradicionais e 24,08\% para pentecostais. Em seguida aparece a camisinha masculina com 13,71\%, $15,53 \%$ e $19,21 \%$ respectivamente. Posteriormente vem a esterilização masculina com 4,65\% para as católicas, 6,08 para as protestantes tradicionais e 7,43 para as pentecostais. O DIU aparece como o método menos utilizado, com 2,34\%, 2,22\% e 0,85\% respectivamente. Já as mulheres sem religião apresentaram um comportamento diferenciado, pois a ordem se modificou um pouco: o método mais utilizado foi a pílula (27,30\%), o segundo a esterilização feminina (19,74\%), o terceiro a camisinha masculina (18,09\%), o quarto a injeção contraceptiva com 9,21\%, e o quinto a esterilização masculina (4,93\%) e por último o DIU, com 2,96\%. Os dados também mostram que as mulheres evangélicas fazem maior uso de contracepção tradicional.

Neste estudo analisou-se a conversão e a frequência a cultos e cerimônias religiosas porque acredita-se que essas são variáveis importantes em estudos que envolvem religião. Os dados da tabela 2 abaixo mostram que as mulheres católicas possuem menor frequência a cultos e missas, 52,24\% frequentam até 3 vezes no mês. Em contrapartida, as evangélicas possuem alta frequência, 75,38\% das protestantes tradicionais e $77,28 \%$ das pentecostais frequentam 1 ou mais vezes por 
semana. Surpreendentemente, 30\% das mulheres sem religião parecem frequentar cultos e cerimônias religiosas, sugerindo que apesar de não adotarem uma igreja não significa que elas não têm religiosidade. A análise da conversão mostra que a maior parte das católicas nunca se converteu, enquanto que entre as evangélicas, 57,91\% das protestantes tradicionais já se converteram e 64,41\% das pentecostais, resultados já esperado e descrito em outros estudos (ALVES e NOVELINO, 2006).

Tabela 2 - Distribuição percentual de mulheres sexualmente ativas, segundo religião atual, conversão e frequência à cultos e cerimônias religiosas, Brasil 2006.

\begin{tabular}{|c|c|c|c|c|c|c|c|}
\hline & Variáveis de religiosidade & católica & protestante & pentecostal & $\begin{array}{c}\text { sem } \\
\text { religião }\end{array}$ & outras & Total \\
\hline \multirow{4}{*}{$\begin{array}{c}\text { Frequência a } \\
\text { cultos e } \\
\text { cerimônias } \\
\text { religiosas }\end{array}$} & uma ou mais vezes na semana & 32,69 & 75,38 & 77,8 & 5,4 & 56,78 & 42,47 \\
\hline & Até três vezes ao mês & 52,24 & 21,92 & 19,22 & 25,86 & 27,44 & 41,04 \\
\hline & nunca & 15,08 & 2,7 & 2,98 & 68,74 & 15,78 & 16,49 \\
\hline & total & 100 & 100 & 100 & 100 & 100 & 100 \\
\hline \multirow{3}{*}{ Conversão } & convertidas & 2,13 & 57,91 & 64,61 & 87,32 & 73,67 & 27,37 \\
\hline & nunca convertidas & 97,87 & 42,09 & 35,39 & 12,68 & 26,33 & 72,63 \\
\hline & total & 100 & 100 & 100 & 100 & 100 & 100 \\
\hline
\end{tabular}

A tabela 3 abaixo mostra a influência da conversão no uso de métodos contraceptivos. Os dados mostram que, de modo geral, ser ou não convertida não altera muito o padrão de uso de métodos contraceptivos. Em todas as categorias religiosas mais de 80\% das mulheres fazem uso de contracepção. Entretanto, a análise do tipo de contracepção mostra diferenciais. Entre as mulheres não convertidas, de forma geral, o uso de hormônios e camisinha é maior. O método tradicional também é maior para as pentecostais $(10,69 \%)$ e para as sem religião (15,16\%). Entre as convertidas, o uso de esterilização é maior. 
Tabela 3 - Distribuição percentual de mulheres sexualmente ativas, segundo religião atual e conversão de acordo com uso e tipos de métodos contraceptivos, Brasil 2006

\begin{tabular}{|c|c|c|c|c|c|c|c|c|c|}
\hline \multirow{2}{*}{\multicolumn{2}{|c|}{$\begin{array}{c}\text { Conversão e religião } \\
\text { atual }\end{array}$}} & \multicolumn{2}{|c|}{$\begin{array}{l}\text { usa algum } \\
\text { método }\end{array}$} & \multirow[t]{2}{*}{ Total } & \multicolumn{4}{|c|}{ tipo de método que usa } & \multirow[t]{2}{*}{ Total } \\
\hline & & $\operatorname{sim}$ & não & & esterilização & hormônios & camisinha & tradicionais & \\
\hline \multirow{6}{*}{ 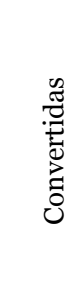 } & católica & 90,37 & 9,63 & 100,00 & 31,74 & 42,13 & 20,52 & 5,61 & 100,00 \\
\hline & protestante & 81,23 & 18,77 & 100,00 & 44,05 & 30,69 & 19,86 & 5,39 & 100,00 \\
\hline & pentecostal & 87,06 & 12,94 & 100,00 & 43,03 & 30,30 & 23,35 & 3,32 & 100,00 \\
\hline & sem religião & 81,63 & 18,37 & 100,00 & 22,82 & 46,25 & 27,45 & 3,48 & 100,00 \\
\hline & outras & 82,09 & 17,91 & 100,00 & 28,45 & 27,05 & 41,07 & 3,43 & 100,00 \\
\hline & total & 83,51 & 16,49 & 100,00 & 35,43 & 34,56 & 25,96 & 4,05 & 100,00 \\
\hline \multirow{6}{*}{ 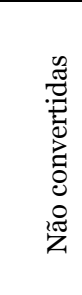 } & católica & 86,48 & 13,52 & 100,00 & 33,84 & 38,52 & 22,08 & 5,53 & 100,00 \\
\hline & protestante & 80,80 & 19,20 & 100,00 & 27,38 & 37,54 & 28,83 & 6,25 & 100,00 \\
\hline & pentecostal & 88,93 & 11,07 & 100,00 & 33,77 & 27,22 & 28,32 & 10,69 & 100,00 \\
\hline & sem religião & 70,41 & 29,59 & 100,00 & 16,87 & 46,63 & 21,34 & 15,16 & 100,00 \\
\hline & outras & 84,36 & 15,64 & 100,00 & 25,02 & 38,01 & 31,12 & 5,84 & 100,00 \\
\hline & total & 85,94 & 14,06 & 100,00 & 33,03 & 37,88 & 23,08 & 5,99 & 100,00 \\
\hline
\end{tabular}

Fonte: Elaboração própria a partir dos dados da PNDS, 2006.

Quando se observa a correlação entre frequência religiosa e contracepção (TAB.4), percebe-se também que não existem grandes diferenças. De forma geral, entre as mulheres que frequentam mais assiduamente há o maior predomínio de uso da esterilização, especialmente entre as evangélicas. Quando estas frequentam menos ou nunca, há o maior uso de hormônios e camisinha.

Esses resultados sugerem que as mulheres mais assíduas não deixam de utilizar método, mas optam por um método definitivo, ou seja, não infringem as normas diariamente, como nos uso dos métodos hormonais e a camisinha. Por outro lado, não se pode esquecer que há uma influência geracional nestes dados, uma vez que a composição etária dos grupos de mulheres que frequentam assiduamente e daquelas que frequentam menos é diferente, sendo que o primeiro é composto por mulheres mais velhas em que a esterilização é mais presente. 
Tabela 4 - Distribuição percentual de mulheres sexualmente ativas, segundo religião atual e frequência a cultos e cerimônias religiosas e uso e tipos de métodos contraceptivos, Brasil 2006.

\begin{tabular}{|c|c|c|c|c|c|c|c|c|c|}
\hline \multirow{2}{*}{\multicolumn{2}{|c|}{$\begin{array}{c}\text { Frequência a cultos } \\
\text { e missas e religião } \\
\text { atual }\end{array}$}} & \multicolumn{2}{|c|}{$\begin{array}{l}\text { usa algum } \\
\text { método }\end{array}$} & \multirow[t]{2}{*}{ Total } & \multicolumn{4}{|c|}{ tipo de método que usa } & \multirow[t]{2}{*}{ Total } \\
\hline & & $\operatorname{sim}$ & não & & esterilização & hormônios & camisinha & tradicionais & \\
\hline \multirow{6}{*}{$\begin{array}{c}\text { uma ou } \\
\text { mais } \\
\text { vezes na } \\
\text { semana }\end{array}$} & católica & 87,85 & 12,15 & 100,00 & 35,82 & 33,52 & 25,05 & 5,61 & 100,00 \\
\hline & protestante & 79,43 & 20,57 & 100,00 & 42,30 & 29,86 & 22,97 & 4,86 & 100,00 \\
\hline & pentecostal & 88,16 & 11,84 & 100,00 & 43,07 & 27,13 & 24,22 & 5,59 & 100,00 \\
\hline & sem religião & 80,72 & 19,28 & 100,00 & 39,27 & 52,06 & 4,37 & 4,29 & 100,00 \\
\hline & outras & 85,50 & 14,50 & 100,00 & 27,18 & 26,11 & 40,78 & 5,94 & 100,00 \\
\hline & total & 85,79 & 14,21 & 100,00 & 38,08 & 31,06 & 25,40 & 5,46 & 100,00 \\
\hline \multirow{6}{*}{$\begin{array}{c}\text { três } \\
\text { vezes ou } \\
\text { menos } \\
\text { por mês }\end{array}$} & católica & 86,24 & 13,76 & 100,00 & 33,04 & 42,00 & 18,92 & 5,98 & 100,00 \\
\hline & protestante & 86,33 & 13,67 & 100,00 & 23,65 & 42,03 & 26,69 & 7,62 & 100,00 \\
\hline & pentecostal & 87,43 & 12,57 & 100,00 & 25,55 & 39,36 & 29,90 & 5,20 & 100,00 \\
\hline & sem religião & 86,11 & 13,89 & 100,00 & 26,14 & 45,64 & 26,75 & 1,47 & 100,00 \\
\hline & outras & 81,95 & 18,05 & 100,00 & 33,58 & 34,93 & 30,61 & 0,88 & 100,00 \\
\hline & total & 86,13 & 13,87 & 100,00 & 31,67 & 41,78 & 20,85 & 5,65 & 100,00 \\
\hline \multirow{6}{*}{ nunca } & católica & 84,79 & 15,21 & 100,00 & 31,77 & 38,20 & 26,29 & 3,74 & 100,00 \\
\hline & protestante & 85,04 & 14,96 & 100,00 & 18,23 & 54,25 & 15,46 & 12,06 & 100,00 \\
\hline & pentecostal & 78,01 & 21,99 & 100,00 & 41,99 & 15,51 & 18,71 & 23,79 & 100,00 \\
\hline & sem religião & 77,81 & 22,19 & 100,00 & 18,92 & 46,07 & 28,71 & 6,30 & 100,00 \\
\hline & outras & 74,36 & 25,64 & 100,00 & 18,01 & 36,12 & 42,99 & 2,88 & 100,00 \\
\hline & total & 81,77 & 18,23 & 100,00 & 26,93 & 40,44 & 27,53 & 5,09 & 100,00 \\
\hline
\end{tabular}

Fonte: Elaboração própria a partir dos dados da PNDS, 2006.

Por fim, tem-se a TAB.5 com o resultado dos modelos de regressão logísticas, onde se observa que, mesmo controlando por variáveis de confusão como idade, região, gênero, educação, estratos econômicos, etc., existem diferenças quanto ao uso de métodos contraceptivos.

As mulheres que apresentam maiores chances de usarem contracepção moderna são católicas, com escolaridade superior a 8 anos de estudo, pertencentes aos estratos econômica A e B, que já possuem filhos vivos, residentes na área urbana, que tem acesso a mídia, que conversam com o marido sobre planejamento familiar e que decidem conjuntamente com o marido sobre questões de administração de recursos da família. As protestantes tradicionais apresentam menor chance de usarem contracepção, 20,5\%. Os valores para as pentecostais e mulheres sem religião não foram significativas. 
A análise por tipo de contracepção mostra que as protestantes tradicionais apresentam maior chance $(31,6 \%)$ de estarem esterilizadas quando comparadas com as católicas. Entretanto, os valores para as pentecostais e mulheres sem religião não foram significativas.

Com relação aos contraceptivos hormonais, os valores para as protestantes tradicionais e mulheres sem religião não foram significativas. Entretanto, as pentecostais apresentam 42\% menor chance de usarem hormônios em relação às católicas. A análise do uso de camisinha revelou que as protestantes tradicionais e as pentecostais apresentam as maiores chances de uso quando comparados às católicas, 34,6\% e 78,4\% respectivamente. Quanto ao modelo sobre métodos tradicionais, surpreendentemente, este não identificou diferenças significativas entre os grupos de religião.

A análise para frequência religiosa só se mostrou significativa para uso de contracepção moderna. As mulheres que frequentam uma ou mais vezes por semana a cultos e missas tem 34,1\% menos chance de usar contracepção quando comparadas às que nunca frequentam. Já as mulheres nunca convertidas apresentam 96\% mais chance de usar o método tradicional.

O comportamento reprodutivo e a escolha do tipo de método não se dão da mesma maneira nas regiões do País. Mulheres residentes nas regiões Sul e Sudeste, as mais desenvolvidas do Brasil, têm as maiores chances de usar métodos, especialmente aqueles hormonais (reversíveis), do que aquelas residentes na região Norte; e por outro lado mulheres do Sul e Sudeste possuem menos chances de estarem esterilizadas quando comparadas àquelas do Norte. Dados muito similares foram encontrados no estudo de Tavares (2006) e mostram que ainda permanece a maior oferta dos serviços de saúde nas regiões mais desenvolvidas, resultando num maior mix de contraceptivos para escolha das mulheres. Não por acaso, no Brasil existe uma elevada taxa de descontinuação de métodos contraceptivos reversíveis, 
quando os mesmos são usados sem o devido acompanhamento médico. Nas regiões menos desenvolvidas a esterilização pode ser a opção mais eficaz para evitar uma gravidez indesejada ou um aborto provocado (Costa apud Tavares, 2006).

Algumas outras variáveis também se mostraram significativas nestes modelos tais como idade, onde o aumento da idade faz diminuir as chances de uso de alguns métodos, nesse caso os métodos hormonais, contudo eleva as chances das mulheres estarem esterilizadas, usarem camisinha e ainda utilizarem métodos tradicionais. A variável raça/cor também se mostrou relevante para explicar ao uso de métodos, onde as mulheres brancas apresentavam maiores chances de uso quando comparadas às demais mulheres, mas por outro lado, essas apresentavam menores chances de terem feito laqueadura e mais chances de uso de algum método tradicional quando comparadas às mulheres dos demais grupos de raça/cor. Quanto maior a escolaridade, mais intensas eram as chances das mulheres utilizarem métodos contraceptivos; e, paralelamente, menor escolaridade maior o uso da esterilização, evidenciando um acesso dificultado dos mix contraceptivo entre as mulheres nas categorias mais baixas de instrução. Entretanto, o nível de escolaridade da mulher não se mostrou estatisticamente significativo em relação à escolha dos demais métodos contraceptivos reversíveis (hormonais, camisinhas e tradicionais). Comportamento semelhante é observado em relação à variável número de filhos vivos, em que a cada filho nascido vivo aumentam as chances de uso de algum método, e 2 vezes a chance da mulher ter sofrido uma laqueadura; contudo, esse efeito não é observado para os outros métodos. Dados parecidos foram observados por Tavares (2006) em estudo com os dados de 1996; a autora sugere que esses resultados evidenciam a falta de opções ou mesmo dificuldades de se lidar com os demais métodos contraceptivos reversíveis dentre todas as mulheres brasileiras independentemente dos respectivos níveis de escolaridade e número de filhos. 
Sabe-se que o uso de métodos está bastante relacionado com a satisfação das preferências reprodutivas, pois mulheres que já alcançaram ou até mesmo ultrapassaram o número de filhos desejados apresentaram maiores chances de uso de algum método contraceptivo. Além disso, relações de gênero e empoderamento das mulheres também podem interferir nesta decisão; isso pode ser visto entre mulheres sobre as quais outras pessoas têm a palavra final; elas apresentaram menores chances de utilizar algum método quando comparadas àquelas que possuem, elas mesmas, a palavra final nas decisões. Nesse mesmo sentido, quando outras pessoas decidem o que fazer com o dinheiro que a mulher ganha, esta apresenta 3 vezes mais chances de estar esterilizada do que aquelas que tomam as decisões por si mesmas. $\mathrm{O}$ acesso à mídia e à informação, como esperado, aumenta as chances da mulher utilizar algum método, em especial os hormonais, quando comparadas às mulheres que não têm estão expostas diariamente à mídia. 
Tabela 5 - Regressões Logistíscias Binomias para dem ostrar a relação entre a religião e o u so de diferentes tipos de contraceptivos, Brasil 2006.

\begin{tabular}{|c|c|c|c|c|c|c|c|c|c|c|}
\hline \multirow[t]{2}{*}{$\begin{array}{c}\text { Variáveis } \\
\text { independentes }\end{array}$} & \multicolumn{2}{|c|}{$\begin{array}{l}\text { Uso de métodos } \\
(0, \text { não 1, sim }) \\
n=8627\end{array}$} & \multicolumn{2}{|c|}{$\begin{array}{c}\text { esterilizada } \\
(0, \text { não 1, sim }) \\
n=4141\end{array}$} & \multicolumn{2}{|c|}{$\begin{array}{c}\text { hormônios } \\
(\text { o, não 1, sim }) \\
\text { n= } \mathbf{4 1 4 1}\end{array}$} & \multicolumn{2}{|c|}{$\begin{array}{c}\text { camisinha } \\
(0, \text { não 1, sim }) \\
n=4141\end{array}$} & \multicolumn{2}{|c|}{$\begin{array}{c}\text { tradicionais } \\
(0, \text { não 1, sim }) \\
n=4141\end{array}$} \\
\hline & Odds Ratio & $\mathbf{P}>|\mathbf{t}|$ & Odds Ratio & $\mathbf{P}>|\mathbf{t}|$ & Odds Ratio & $\mathbf{P}>|\mathbf{t}|$ & Odds Ratio & $\mathbf{P}>|\mathbf{t}|$ & Odds Ratio & $\mathbf{P}>|\mathbf{t}|$ \\
\hline \multicolumn{11}{|l|}{ Região geográfica } \\
\hline Norte & \multicolumn{10}{|c|}{ Referência } \\
\hline Nordeste & 1,979 & 0,000 & 0,787 & 0,111 & 1,816 & 0,001 & 0,582 & 0,002 & 0,877 & 0,622 \\
\hline Sudeste & 1,622 & 0,004 & 0,287 & 0,000 & 2,328 & 0,000 & 0,468 & 0,000 & 0,689 & 0,135 \\
\hline Sul & 1,837 & 0,001 & 0,233 & 0,000 & 4,370 & 0,000 & 0,320 & 0,000 & 0,445 & 0,002 \\
\hline Centro-Oeste & 1,834 & 0,000 & 0,828 & 0,170 & 2,545 & 0,000 & 0,526 & 0,000 & 0,323 & 0,000 \\
\hline \multicolumn{11}{|l|}{ situação de domicílio } \\
\hline urbano & \multicolumn{10}{|c|}{ Referência } \\
\hline rural & 0,908 & 0,429 & 1,027 & 0,841 & 1,414 & 0,017 & 0,707 & 0,016 & 0,666 & 0,086 \\
\hline idade & 0,865 & 0,000 & 1,647 & 0,000 & 0,734 & 0,000 & 1,104 & 0,018 & 1,440 & 0,000 \\
\hline ser casada/unida & (omitted) & & (omitted) & & & & (omitted) & & (omitted) & \\
\hline filhos nascidos vivos & 1,555 & 0,000 & 2,192 & 0,000 & 0,980 & 0,795 & 1,046 & 0,560 & 1,070 & 0,530 \\
\hline \multicolumn{11}{|l|}{ escolaridade } \\
\hline o a 3 & \multicolumn{10}{|c|}{ Referência } \\
\hline 4 a 7 & 1,307 & 0,102 & 0,765 & 0,100 & 0,740 & 0,195 & 1,397 & 0,139 & 1,180 & 0,591 \\
\hline 8 a 10 & 2,267 & 0,000 & 0,740 & 0,096 & 0,835 & 0,430 & 1,425 & 0,115 & 0,929 & 0,833 \\
\hline 11 & 2,092 & 0,000 & 0,738 & 0,110 & 0,828 & 0,425 & 1,420 & 0,133 & 1,339 & 0,399 \\
\hline 12 e mais & 2,803 & 0,000 & 0,662 & 0,067 & 0,894 & 0,699 & 1,198 & 0,537 & 1,302 & 0,527 \\
\hline \multicolumn{11}{|l|}{ raça/cor } \\
\hline não branca & & & & & Referê & & & & & \\
\hline branca & 1,207 & 0,098 & 0,794 & 0,037 & 0,856 & 0,295 & 0,942 & 0,668 & 1,417 & 0,077 \\
\hline estratos econômicos & & & & & & & & & & \\
\hline A e B & & & Referência & & & & & & & \\
\hline C & 0,945 & 0,642 & 1,058 & 0,707 & 1,294 & 0,134 & 0,721 & 0,086 & 1,016 & 0,951 \\
\hline DeE & 0,666 & 0,005 & 1,008 & 0,965 & 1,092 & 0,679 & 0,654 & 0,05 & 1,143 & 0,662 \\
\hline religião & & & & & & & & & & \\
\hline católicas & & & & & Referê & & & & & \\
\hline protestante tradicional & 0,795 & 0,051 & 1,316 & 0,073 & 0,790 & 0,194 & 1,346 & 0,076 & 0,852 & 0,555 \\
\hline pentecostal & 0,950 & 0,689 & 1,185 & 0,269 & 0,578 & 0,009 & 1,784 & 0,018 & 1,080 & 0,817 \\
\hline sem religião & 0,893 & 0,457 & 0,731 & 0,160 & 0,767 & 0,194 & 1,197 & 0,376 & 0,961 & 0,912 \\
\hline outras & 0,520 & 0,000 & 1,047 & 0,869 & 0,775 & 0,325 & 1,821 & 0,023 & 0,611 & 0,256 \\
\hline frequência & & & & & & & & & & \\
\hline nunca & & & & & Referêt & & & & & \\
\hline até 3 vezes por mês & 0,879 & 0,389 & 1,000 & 0,995 & 1,038 & 0,763 & 0,869 & 0,313 & 1,147 & 0,526 \\
\hline 1 ou mais vezes por semana & 0,659 & 0,044 & 1,137 & 0,483 & 0,763 & 0,154 & 1,214 & 0,308 & 0,963 & 0,902 \\
\hline conversão & & & & & & & & & & \\
\hline $\operatorname{sim}$ & & & & & Referê & & & & & \\
\hline não & 1,04 & 0,838 & 0,895 & 0,512 & 0,805 & 0,246 & 0,955 & 0,82 & 1,96 & 0,035 \\
\hline situação de fecundidade & & & & & & & & & & \\
\hline tem menos filhos que o dese & & & & & Referê & & & & & \\
\hline tem o número de filhos dese & 2,929 & 0,000 & 1,646 & 0,000 & 1,233 & 0,141 & 0,924 & 0,590 & 0,658 & 0,044 \\
\hline tem mais filhos do que o des & 2,614 & 0,000 & 0,959 & 0,799 & 1,315 & 0,256 & 0,761 & 0,276 & 0,663 & 0,249 \\
\hline $\begin{array}{l}\text { diferença de idade entre } \\
\text { mulher e companheiro }\end{array}$ & 1,007 & 0,188 & 1,003 & 0,698 & 0,988 & 0,174 & 1,013 & 0,123 & 1,006 & 0,649 \\
\hline decisão sobre o dinheiro que & e a mulher gar & a e uso d & metodos con & raceptivc & & & & & & \\
\hline ela decide & & & & & Referề & & & & & \\
\hline ele decide & 2,771 & 0,000 & 0,737 & 0,202 & 0,390 & 0,000 & 2,249 & 0,001 & 2,396 & 0,032 \\
\hline os dois decidem & 8,482 & 0,000 & 0,754 & 0,024 & 0,407 & 0,000 & 1,869 & 0,000 & 1,976 & 0,004 \\
\hline outros & 8,008 & 0,000 & 4,314 & 0,000 & 0,732 & 0,645 & 0,869 & 0,850 & 3,566 & 0,072 \\
\hline palavra final (própria saúde, & saúde dos fill & $\mathrm{s}, \mathrm{comp}$ & as de valor ele & ado, com & ida preparada & liariamen & e, visitas à par & entes e al & & \\
\hline ela tem & & & & & Referê & & & & & \\
\hline ele tem & 0,987 & 0,94 & 1,007 & 0,974 & 1,562 & 0,136 & 0,594 & 0,065 & 0,511 & 0,136 \\
\hline os dois tem & 1,053 & 0,73 & 1,113 & 0,625 & 1,227 & 0,395 & 0,77 & 0,299 & 0,693 & 0,338 \\
\hline outros & 0,664 & 0,006 & 1,157 & 0,542 & 1,02 & 0,939 & 0,846 & 0,508 & 0,791 & 0,526 \\
\hline conversa sobre planejament & to familiar con & o marido & & & & & & & & \\
\hline não & & & & & Referê & & & & & \\
\hline sim & 1,791 & 0,013 & 0,797 & 0,085 & 1,073 & 0,615 & 0,902 & 0,454 & 0,893 & 0,609 \\
\hline acesso diário à mídia (tv, rád & dio ou jornal) & & & & & & & & & \\
\hline não & & & & & Referêt & & & & & \\
\hline $\operatorname{sim}$ & 1,4651 & 0,067 & 1,321 & 0,188 & 1,912 & 0,025 & 0,558 & 0,037 & 0,46 & 0,105 \\
\hline Fonte: Microdados PNDS 200 & 006 & & & & & & & & & \\
\hline
\end{tabular}




\section{Considerações finais}

As doutrinas e ensinamentos religiosos podem influenciar de várias maneiras o comportamento demográfico dos fiéis, alterando o estilo de vida e influenciando as suas preferências e escolhas quanto ao uso e tipo de métodos contraceptivos a serem adotados. Com esta premissa, o objetivo deste artigo foi identificar e analisar os possíveis diferenciais no uso de contracepção segundo grupos religiosos no Brasil.

E respondendo aos questionamentos feitos inicialmente, pode-se dizer que o percentual de mulheres que usavam contraceptivos é bastante elevado. Entretanto, a prática contraceptiva é diferenciada de acordo com a categoria religiosa da mulher já que as católicas utilizavam mais contracepção moderna que as evangélicas.

A frequência a cultos e cerimônias podem afetar o uso de contracepção. Observa-se que as mulheres da religião católica possuem baixa freqüência às missas e atividades religiosas, o que reflete em seu grau de comprometimento com os ensinamentos e recomendações do catolicismo sobre o comportamento contraceptivo, levando-as a praticarem o uso da contracepção moderna apesar de estarem em desacordo com as doutrinas católicas. Porém, entre as evangélicas, que são mais assíduas às igrejas, percebe-se uma maior influência doutrinária no uso da contracepção moderna, utilizada em menor proporção quando comparada às católicas.

Estes dados descritivos foram reforçados pela análise do modelo de regressão logística binomial que mostrou diferenciais quando ao uso e tipo de método adotado. As protestantes tradicionais, apesar de no modelo geral apresentarem menores chances de uso de métodos, foram as únicas que apresentaram maior probabilidade de estarem esterilizadas quando comparadas às católicas, o que remete à possibilidade de que estas mulheres optem por um 
método não reversivo, o qual é feito uma única vez, movidas pelo sentimento de estar indo menos contra as normas de suas igrejas, além de se resguardarem quanto à opção por não ter mais filhos. A preferência pela esterilização poderia ser vista, nesse caso, como a melhor opção entre os métodos contraceptivos disponíveis dentro do contexto de vida religiosa destas mulheres.

A análise dos modelos mostrou também que mulheres que apresentam alta frequência a cultos e missas utilizam menos contracepção moderna e as nunca convertidas usam mais métodos tradicionais.

Outras variáveis de contexto também parecem interferir no processo da escolha por contraceptivos, em que a escolaridade, o estrato econômico, a experiência reprodutiva (filhos tidos e alcance do número de filhos ideal) e o contexto de empoderamento da mulher parecem ter um impacto bastante expressivo, não somente para a utilização ou não de algum contraceptivo, mas também para determinação de qual tipo de método adotar.

Acredita-se que este estudo possibilitou vislumbrar a influência da religião perante as decisões contraceptivas e entender um pouco mais sobre como as normas e valores transmitidos aos seguidores atuam, assim como outros mediadores, nas decisões acerca do comportamento reprodutivo das mulheres religiosas. Recomenda-se a exploração das questões religiosas e seus impactos em outras áreas de comportamento reprodutivo, tais como taxa de fecundidade, demanda insatisfeita por contracepção, entre outras, a fim de expandir os conhecimentos acerca da importância de afiliação religiosa sobre o campo demográfico.

\section{REFERÊNCIAS}

AGADJANIAN, V. Religion, Social Milieu, and the Contraceptive Revolution. Population Studies, Britain, v. 55, n. 2 , p. 135-148, Jul., 2001.

\section{AGUIRRE, M. A. C. Estudo dos componentes da dinâmica reprodutiva na}

Bolívia, 1998. Tese (Doutorado em Demografia), Universidade Federal de Minas Gerais, 2003. 
ALVES , J. E. D.; NOVELLINO , M. S. A dinâmica das filiações religiosas no Rio de Janeiro: 1991-2000 - um recorte por educação, cor, geração e gênero. In: PATARRA, N.; AJARA, C.; SOUTO, J. O Rio de Janeiro continua sendo... Rio de Janeiro: Ence/IBGE, 2006. p. 275-308.

AMORIM, F. A. Mudanças recentes no uso de métodos contraceptivos no Brasil: a questão da esterilização voluntária, 2009. Dissertação (Mestrado em Estudos Populacionais e Pesquisa Sociais), Escola Nacional de Ciências Estatísticas, 2009.

BANKOLE, A.; WESTOFF, C.F. The consistency and validity of reproductive attitudes: Evidence from Morocco. Journal of Biosocial Science, Cambridge, v. 30, n. 4, p. 439455, 1998.

BARROS, J.V.S; WONG, L.L.R. Prevalência, conhecimento e uso de métodos contraceptivos segundo tipo de união das mulheres: um estudo para Brasil e México. Anais [recurso eletrônico] / XVIII. Encontro Nacional de Estudos Populacionais:transformações na população brasileira: complexidades, incertezas e perspectivas,19 a 23 de novembro de 2012 / Águas de Lindóia, SP: ABEP, 2012.

DOCTOR, H. V., PHILLIPS, J. F.; SAKEAH, E. The Influence of Changes in Women's Religious Affiliation on Contraceptive Use and Fertility Among the Kassena-Nankana of Northern Ghana. Studies in Family Planning, New York, v. 40, n. 2, p. 113-122, June 2009.

ELLISON, C.G.; LEVIN, J.S. The The Religion-Health Connection: Evidence, Theory, and Future Directions. Health Education Behavior, Columbia, 25, p. 700-720, 1998.

GODSCHEIDER; C.; MOSHER, W. D. Religious affiliation and contraceptive usage: Changing American patterns, 1955-82. Studies in Family Planning, Brown University, Providence, v. 19, n. 1, p. 48-57, 1988.

GUJARATI, D. Econometria básica. Tradução da 4. ed. por Mariua José Cyhlar Monteiro. Rio de Janeiro: Elsevier, 2006 - 3. Reimpressão.

INSTITUTO BRASILEIRO DE GEOGRAFIA E ESTATÍSTICA - IBGE. 2010. Religião. Características gerais da população, religião e pessoas com deficiência. Rio de Janeiro: IBGE, 2010.

IYER, S. Religion and the Decision to Use Contraception in India. Journal for the Scientific Study of Religion, Indianapolis, v. 41, n. 4, p. 711-722, Dec., 2002.

JARDIM, R. T. Entre a Lei de Deus e a Lei Humana: A constante construção da laicidade no Brasil. Disponível em: <http://www4.cmq.edu.mx/libela_joomla/images/stories/cursos/ivcurso/ENTRE\%20A\% 20LEI\%20DE\%20DEUS\%20E\%20A\%20LEI\%20HUMANA\%20[Renata\%20Jardim].pdf>. Acesso em: 06 out. 2011. 
KRAUSE, N.; ELLISON, C.; WULFF, K. Church-based emotional support, negative interaction, and psychological wellbeing: findings from a national sample of presbyterians. Journal for the Scientific Study of Religion, Indianapolis, v. 37, n. 4, p. 725-741, 1998.

KRAUSE, N.; ELLISON, E. The doubting process: a longitudinal study of the precipitants and consequences of religious doubt in older adults. Journal for the Scientific Study of Religion, Indianapolis, v. 48, n. 2, p. 293-312, 2009.

McKINNON, S.; POTTER, J.; GARRARD-BURNETT, V. Adolescent fertility and religion in Rio de Janeiro, Brazil in the year 2000: the role of Protestantism. Population Studies, Britain, v. 62, n. 3, p. 289-303, 2008.

McQUILlAN, K. When Does Religion Influence Fertility? Population and Development Review, New York, Vol. 30, No. 1, pp. 25-56, 2004.

MIRANDA-RIBEIRO, P.; LONGO, L. A. F. B.; RIOS-NETO, E. L. G.; POTTER, J. E. Fecundidade na adolescência e religião em Belo Horizonte: um primeiro exercício.

Revista Brasileira de Estudos de População, Rio de Janeiro, v. 26, n. 2, p. 305-308, 2009.

PEDRO, J. M. A experiência com contraceptivos no Brasil. Revista Brasileira de História, São Paulo, v. 23, n. 45, p. 239-260, 2003.

PERPÉTUO, I. H. O.; AGUIRRE, M. A. C. O papel da esterilização feminina nos diferenciais socioeconômicos do declínio da fecundidade no Brasil. Anais... ABEP. 1998. Disponível em: <http://www.abep.org.br/index.htm> Acesso em: 16 jul. 2008.

PERPÉTUO, I. H. O.; WONG, L. Desigualdade socioeconômica na utilização de métodos anticoncepcionais no Brasil: uma análise comparativa com base nas PNDS 1996 e 2006. Dimensões do processo reprodutivo e da saúde da criança. Pesquisa Nacional de Demografia e Saúde da Criança e da Mulher: PNDS 2006. Cebrap, Ministério da Saúde, 2009.

PERPÉTUO, I.H. O.; WAJNMAN, S. A esterilização feminina no Brasil: diferenciais por escolaridade e renda. Revista Brasileira de Estudos de População, Rio de Janeiro, v. 10, n. 1/2, p. 25-39, 1993 .

PNDS. MINISTÉRIO DA SAÚDE/Centro Brasileiro de Análise e Planejamento (CEBRAP). Pesquisa Nacional de Demografia e Saúde da Criança e da Mulher: PNDS 2006. Brasília, 2012. Disponível em:<http://bvsms.saude.gov.br/bvs/pnds/> Acesso em: 4 fev. 2012.

REGNERUS, M. D. Religion and positive adolescent outcomes: a review of research and theory. Review of Religious Research, Galva, v.44, n. 4, p. 394-413, 2003.

SANTOS, E.C. Comportamento sexual e religiosidade: um estudo com jovens brasileiros. 2008. 129f. Tese (doutorado em Psicologia) - Programa de Pós-graduação em Psicologia, Universidade Federal do Rio Grande do Sul. 
SOCIEDADE MISSIONÁRIA LUTERANA. Trazendo Cristo às Nações e as Nações a Cristo. [2012]. Disponível em:

<http://www.google.com.br/url?sa=t\&rct=j\&q=\&esrc $=$ s\&frm $=1 \&$ source $=$ web\&cd $=1 \& v e d=$ oCBoQFjAA\&url=http\%3A\%2F\%2Fwww.horaluterana.org.br\%2Fquem-

somos\%2F\&ei=aRg8VPyNB9PKggTW-YL4Ag\&usg=AFQjCNGLFoSkaw6b2P-

vB_W5C7RGECmw7g\&bvm=bv.77161500,d.eXY>. Acesso em: 13 out. 2014.

SOUZA, V. J. O aborto no Brasil: um resgate das concepções morais católicas em contraposição aos grupos pró-aborto. Anais do II encontro nacional do GT história das religiões e das religiosidades revista brasileira de história das religiões ANPUH. Maringá (PR), v. 1, n. 3, 2009. ISSN 1983-2859. Disponível em: <http://www.dhi.uem.br/gtreligiao/pub.html>. Acesso em: o9 out. 2014.

SRIKANTHAN, A.; REID, R. L. Religious and Cultural Influences on Contraception. Journal of Obstetrics Gynaecology, London, v. 30, n.2, p. 129-137, 2008.

TAVARES, L. S. Demanda total por anticoncepção no Brasil: uso e necessidade insatisfeita por métodos anticoncepcionais. 2006. 101f. Dissertação (Mestrado em Saúde Pública). Escola Nacional de Saúde Púbica Sérgio Arouca, Fundação Oswaldo Cruz, Rio de Janeiro.

UNFPA STATE OF WORLD POPULATION 2005. Disponível em:

<http://www.unfpa.org/swp/2005/images/e_indicator1.pdf>. Acesso em: 07 mar. 2006.

UNITED NATIONS. Report of the International Conference on Population and Development. Cairo, set. 1994. Disponível em:

<http://www.unfpa.org/icpd/docs/icpd/conference-report/fi nalreport_icpd_eng.pdf>. Acesso em: 15 de fev. de 2012.

VERONA, A. P. A.; HUMMER, R.; DIAS JUNIOR, C. S.; LIMA, L. Infant mortality and mothers' religious involvement in Brazil. Revista Brasileira de Estudos de População, Rio de Janeiro, v. 27, n. 1, p. 59-74, 2010.

VERONA, A. P. Explanations for religious influence on adolescent sexual behavior in Brazil: direct and indirect effects. Revista Brasileira de Estudos de População, Rio de Janeiro, v. 28, n. 1, p. 187-201, 2011.

WOOD, C.; WILLIAMS, P.; CHIJIWA , K. Protestantism and child mortality in Northeast Brazil, 2000. Journal for the Scientific Study of Religion, Indianapolis, v. 46, n. 3, p. 405-416, 2007.

ZANATA, R. C. A carne é fraca: religião, religiosidade e iniciação sexual entre estudantes do Ensino Médio na Região Metropolitana de Belo Horizonte, 2008. Dissertação (Mestrado em Demografia), Universidade Federal de Minas Gerais, 2011. 